\title{
PENGARUH ABSENSI SIDIK JARI (FINGER PRINT) DAN MOTIVASI KERJA TERHADAP KEDISIPLINAN PEGAWAI PADA DP2KBP3A KABUPATEN AGAM
}

\author{
Muhammad Nur ${ }^{1 *}$ Rahmi Aini ${ }^{2}$ \\ ${ }^{1}$ Jurusan Teknik Industri, Fakultas Sains dan Teknologi, Universitas Islam Negeri Sultan Syarif Kasim Riau, Pekanbaru- \\ Indonesia \\ *Corresponding Author: muhammad.nur@uin-suska.ac.id
}

\begin{abstract}
Abstrak -Dinas Pengendalian Penduduk Keluarga Berencana Pemberdayaan Perempuan dan Perlindungan Anak Kab. Agam adalah kantor yang membantu Bupati melaksanakan urusan pemerintahan yang menjadi kewenangan daerah dan tugas pembantuan di bidang pengendalian penduduk dan keluarga berencana dan bidang pemberdayaan perempuan dan perlindungan anak. Pada kantor tersebut masih banyak pegawai yang telat dan tidak hadir pada waktu bekerja. Pada hal kantor tersebut sudah menggunakan absensi sidik jari (finger print). Penerapan sistem absensi sidik jari (finger print) dan motivasi kerja apakah berpengaruh terhadap peningkatan kedisiplinan pegawai dan sejauh mana hubungan antara penerapan absensi sidik jari (finger print) dan motivasi kerja terhadap peningkatan kedisiplinan pegawai. Untuk mengetahui hal tersebut maka dilakukan uji asumsi klasik, uji regresi linear berganda, dan pengujian hipotesis. Sehingga hasil dari uji tersebut adalah penerapan absensi sidik jari (finger print) tidak mempengaruhi kedisiplinan pegawai tetapi motivasi kerja mempunyai pengaruh terhadap kedisiplinan pegawai. Absensi sidik jari (finger print) dan motivasi kerja secara bersama-sama mempengaruhi kedisiplinan pegawai sebesar $44,6 \%$.
\end{abstract}

Kata Kunci: Pengujian Hipotesis, Uji Asumsi Klasik, Uji Regresi Linear Berganda.

\section{Pendahuluan}

Perkembangan ilmu pengetahuan dan teknologi yang sangat pesat, membawa perubahan pula dalam kehidupan manusia.Perubahan-perubahan itu membawa akibat yaitu tuntutan yang lebih tinggi terhadap setiap individu untuk lebih meningkatkan kinerja mereka sendiri dan masyarakat luas.Salah satu perkembangan teknologi informasi yang penting adalah semakin dibutuhkannya penggunaan alat pengolah data yang berfungsi untuk menghasilkan informasi yang dibutuhkan.

Teknologi diera globlalisasi kususnya teknologi komputer telah menghasilkan informasi yang lebih cepat, akurat dan lebih relevan.Tidak dapat dipungkiri bahwa teknologi informasi telah menjadi kebutuhan sekaligus persyaratan bagi sebuah organisasi dalam rangka mencapai tujuan yang diinginkan.Teknologi informasi tidak hanya dapat diterapkan pada semua sektor ekonomi saja, tetapi juga dapat berpengaruh pada setiap fungsi dalam organisasi.Dalam organisasi kedisiplinan sangat penting dalam manajemen sumber daya manusia karena semakin baik disiplin pegawai, semakin tinggi pula prestasi kerja yang dicapainya.

Upaya untuk memberikan pendisiplinan tersebut pada dasarnya merupakan upaya untuk peningkatan kinerja pegawai.Peningkatan atas kinerja sangat tergantung pada kesadaran dari tiap-tiap pegawai dan peningkatan tersebut dapat dilihat pada perilaku pada suatu lingkungan kerja yang ada.Dalam upaya untuk meningkatkan kinerja para pegawai perusahaan wajib untuk menjaga keberadaan sumber daya manusia dengan mengefektifkan dan mengefisienkan sumber daya manusia yang telah dimilikinya, dimana salah satu kebijakan yaitu dengan pemberian motivasi kerja dan disiplin kerja pada pegawai agar bekerja secara maksimal diperusahaan [6]. 
Dalam rangka meningkatkan motivasi kerja dan kinerja pegawai, maka upaya pengendalian dan pengawasan kerja perlu dilaksanakan secara terus menerus dan konsisten.Salah satu faktor yang dapat dijadikan sebagai alat pengawasan dan pengendalian adalah melihat tingkat kehadiran pegawai yang secara periodik di evaluasi yaitu dengan sistem pelaporan presensi sidik jari (fingerprint) dimana fungsi alat ini yaitu merekam kehadiran seorang pegawai secara cepat, tepat, dan akurat [5].

Dinas Pengendalian Penduduk Keluarga Berencana Pemberdayaan Perempuan dan Perlindungan Anak merupakan salah satu perangkat daerah yang menjadi Tipe A. Peraturan Bupati Nomor 52 Tahun 2016 tentang penjabaran tugas pokok dan fungsi Dinas Pengendalian Penduduk Keluarga Berencana Pemberdayaan Perempuan dan Perlindungan Kabupaten Agam.

Penelitian ini menerapkan pengaruh efektifitas absensi sidik jari (finger print) dan motivasi kerja terhadap kedisiplinan pegawai pada Dinas Pengendalian Penduduk Keluarga Berencana Pemberdayaan Perempuan dan Perlindungan Anak Kabupaten Agam. Berdasarkan hasil pra riset yang diperoleh dapat diketahui hasil print out pegawai mana yang tingkat absensinya sesuai dengan aturan. Pada kenyataannya masih banyak pegawai yang melakukan pelanggaran.Pegawai masih banyak yang datang terlambat atau bekerja tidak sesuai dengan waktu yang telah ditetapkan. Padahal pada kantor tersebut sudah menerapkan absensi sidik jari (finger print). Dari uraian latar belakang tersebut maka penulis mengadakan suatu penelitian tentang "Pengaruh Absensi Sidik Jari (Finger Print) dan Motivasi Kerja Terhadap Kedisiplinan Pegawai" pada Dinas Pengendalian Penduduk Keluarga Berencana Pemberdayaan Perempuan dan Perlindungan Anak Kab. Agam.

\section{Landasan Teori}

\subsection{Uji Validitas dan Reabilitas}

Validitas berasal dari kata validity yang mempunyai arti sejauh mana ketepatan dan kecermatan suatu instrumen pengukur (tes) dalam melakukan fungsi ukurnya.Suatu tes dikatakan memiliki validitas yang tinggi apabila alat tersebut menjalankan fungsi ukur secara tepat atau memberikan hasil ukur yang sesuai dengan maksud dilakukannya pengukurantersebut. Artinya hasil ukur dari pengukuran tersebut merupakan besaran yang mencerminkan secara tepat fakta atau keadaan sesungguhnya dari apa yang diukur [4].

Uji validitas dalam penelitian menggunakan rumus Korelasi Product Moment Pearson sebagai berikut :

$$
r=\frac{n\left(\left(\sum X Y\right)-\left(\sum X\right)\left(\sum Y\right) x^{2}\right.}{\sqrt{n \sum X-\left(X \sum X\right)^{2}\left(n \sum Y^{2}-\left(\sum Y\right)^{2}\right)}}
$$

Keterangan :

$$
\begin{array}{ll}
r & : \text { Koefisien Korelasi produk moment } \\
\sum X & : \text { Jumlah Skor dalam sebaran } X
\end{array}
$$

\section{$\sum Y \quad$ : Jumlah Skor dalam sebaran $Y$}

$\sum \mathrm{X}^{2}$ : Jumlah skor yang dikuadratkan dalam sebaran $\mathrm{X}$ $\sum Y^{2}$ : Jumlah skor yang dikuadratkan dalam sebaran $Y$ $\sum X Y$ : Jumlah hasil kali skor $X$ dan $Y$ yang berpasangan $\mathrm{n}$ : Jumlah Responden

Nilai koefisien korelasi baik skor butir dikotomi maupun skor butir politomi untuk masing-masing butir dibandingkan dengan nilai koefisien korelasi yang ada di tabel-r pada alpha tertentu misalnya $\alpha=0,05$. Jika koefisien korelasi skor butir dengan skor total lebih besar dari koefisien korelasi dari tabel-r, koefisien korelasi butir signifikan dan butir tersebut valid secara empiris [4].

Reliabilitas berasal dari kata reliability berarti sejauh mana hasil suatu pengukuran dapat dipercaya. Suatu hasil pengukuran dapat dipercaya apabila dalam beberapa kali pelaksanaan pengukuran terhadap kelompok subyek yang sama, diperoleh hasil pengukuran yang relatif sama, selama aspek yang diukur dalam diri subyek memang belum berubah [4].

Adapun perhitungan seara manual sebagai berikut:

$r x y=\left[\frac{k}{k-1}\right]\left[1 \frac{\sum \sigma^{2} b}{\sigma^{2}-t}\right]$

Keterangan:

Rxy = realialibilitas instrument

$\mathrm{K}=$ banyak butir pertanyaan

$\sum \sigma^{2} b=$ Jumlah varian butir

$\sigma^{2} \mathrm{~b}=$ total variasi

\subsection{Uji Asumsi Klasik}

Model regresi yang baik harus bebas penyimpangan asumsi klasik. Penyimpangan asumsi klasik terdiri dari :

1. Uji Normalitas

Dengan tujuan untuk dapat mengetahui bahwa data yang ada terdistribusi normal dan independen.Walaupun normalitas suatu data tidak terlalu penting, tetapi sebaiknya data yang ada berkontribusi normal.Uji normalitas menjadi penting dikarenakan dengannormalnya suatu data maka data tersebut dapat dianggap dapat mewakili populasi.Uji normalitas dapat dilakukan dengan menggunakan grafik maupun menggunakan uji statistik [2].

2. Uji Multikolinearitas

Uji Multikolinearitas merupakan keadaaan dimana ada hubungan linier secara sempurna atau mendekatisempurna antara variabel independendalam model regresi. Menurut Hair (2010), variabel yang menyebabkan multikolinearitas dapat dilihat dari nilai toleransi yang lebih kecil dari 0,1 atau nilai VIF yang lebih besar dari nilai 10. Tujuan dilakukan uji multikolinearitas adalah untuk menguji apakah model regresi ditemukan adanya korelasi antar variabel independen.Model regresi yang baik sebaiknya terbebas dari korelasi di antara variabel independen [2]. 
3. Uji Heteroskedastisitas

Uji Heteroskedastisitas adalah varian residual yang tidak sama ada semua pengamatan di dalam model regresidimana regresi yang baik seharusnya tidak terjadi heteroskedasitas. Pengambilan keputusan yaitu dengan cara:

a. Jika ada pola tertentu, seperti titik-titik yang ada membentuk suatu pola tertentu yang teratur (begelombang melebar kemudian menyempit), maka terjadi heteroskedastisitas.

b. Jika tidak ada pola yang jelas, seperti titiktitik yang menyebar di atas dan di bawah angka 0 pada sumbu $Y$, maka tidak terjadi heteroskedastisitas. Dari output regresi titik-titik tidak membentuk pola yang jelas, dan titik-titik menyebar di atas dan di bawah angka 0 pada sumbu $Y$, jadi dapat disimpulkan bahwa tidak terjadi heteroskedastisitas dalam model regresi [2].

4. Uji Regresi Linear Berganda

Analisis regresi linier berganda adalah hubungan secara linier antara dua atau lebih variable independen dengan satu variable dependen yang digunakan untuk memprediksi atau meramalkan suatu nilai variable dependen berdasarkan variable independen.Selain itu, uji regresi linear juga berguna untuk mengukur kekutan hubungan antara dua variabel atau lebih, dan menunjukan arah hubungan variabel dependen dengan variabel independen [2].

$$
\mathrm{Y}=\mathrm{a}+\mathrm{b} 1 \mathrm{X} 1+\mathrm{b} 2 \times 2+\mathrm{e}
$$

Dimana :

$\mathrm{Y}=$ kedisiplinan karyawan

$\mathrm{a}=$ Konstansta

$\mathrm{X} 1$ = penerapan absensi sidik jari (finger print)

$\mathrm{X} 2$ = motivasi

$\mathrm{b}=$ koefisien regresi yaitu besarnya perubahan yang terjadi pada $\mathrm{Y}$, jika satu unit perubahan pada variabel bebas ( variabel $X$ )

$\mathrm{e}=$ Kesalahan pengganggu

\subsection{Pengujian Hipotesis}

Pengujian ini dilakukan untuk melihat pengaruh variabel bebas $(X)$ terhadap $(Y)$ dengan melakukan $u j i t$ untuk melihat pengaruh secara parsial. Berikut penjelasan mengenai kedua hal di atas:

1. Uji t-test

Uji t-test dilakukan untuk melihat pengaruh parsial dari variabel-variabel independen apakah berpengaruh signifikan terhadap variabel dependen.Apabila T hitung lebih besar dari T tabel maka dapat disimpulakan bahwa variabel-variabel independen tersebut berpengaruh secara signifikan terhadap variabel-variabel dependen. Kriteria pengujian jika signifikansi $<0,05$ maka $\mathrm{HO}$ diterima dan jika signifikan $>0,05$, maka Ho ditolak.
2. Koefisien Determinasi

Koefisien determinasi dilakukan dengan tujuan melihat seberapa baik variabel independen menerangkan atau memperjelas keberadaaan variabel dependen.Hal ini dapat terlihat dari nilai koefisien determinasi yang tinggi, maka semakin tinggi pula kemampuan variabel indipenden dalm menjelaskan variabel dependen [2].

\section{Metodologi Penelitian}

3.1 Lokasi dan Waktu Penelitian

Pelaksanaan penelitian dilakukan di Dinas Pengendalian Penduduk Keluarga Berencana Pemberdayaan Perempuan dan Perlindungan Anak Kabupaten Agam, Provinsi Sumatera Barat. Waktu pelaksanaan penelitian dilaksanakan pada tanggal 23 Januari sampai 23 Februari 2019.

\subsection{Instrumen Penelitian}

Instrumen yang digunakan dalam penelitian antara lain pena dan angket pengumpulan data.

\subsection{Sumber Data yang Digunakan}

Sumber data yang digunakan terdiri dari:

1. Data Primer

Data primer adalah data yang diperoleh langsung dari responden (objek penelitian). Data primer dapat diperoleh melalui kuesioner..Kuesioner yaitu berisi daftar pertanyaan-pertanyaan yang jawabannya masih bersifat luas.

2. Data Sekunder

Data sekunder adalah data yang diperoleh melalui data yang telah diteliti. Pada bagian data sekunder ini gambaran umuminformasi didapatkan dari kantor dan yang memperkuat informasi dengan jurnal.

\section{Hasil dan Pembahasan}

\subsection{Uji Asumsi Klasik}

Sebelum melakukan analisis regresi, terlebih dahulu dilakukan uji asumsi klasik yang harus dipenuhi, yaitu :

1. Uji Multikolinearitas

Uji multikolinieritas ini bertujuan untuk mengetahui apakah tiap-tiap variabel bebas yaitu penerapan absensi sidik jari (X1) dan motivasi kerja (X2) saling berhubungan secara linier.Jika ada kecenderungan adanya multikolinearitas maka salah satu variabel memiliki gejala multikolinearitas.Pengujian adanya multikolinearitas ini dapat dilakukan dengan melihat nilai VIF pada masing-masing variabel bebasnya.Jika nilai VIF-nya lebih kecil dari 10 tidak ada kecenderungan terjadi gejala multikolinearitas.

Dari hasil pengujian SPSS diperoleh nilai korelasi antar variabel kedua variabel bebas adalah sebagai berikut : 
Tabel 1.Uji Multikolinearitas

\begin{tabular}{|c|c|c|c|c|c|c|}
\hline & \multirow[b]{2}{*}{ Model } & \multicolumn{2}{|c|}{$\begin{array}{l}\text { Unstandardized } \\
\text { Coefficients }\end{array}$} & \multirow{2}{*}{$\begin{array}{c}\begin{array}{c}\text { Standardized } \\
\text { Coefficients }\end{array} \\
\text { Beta }\end{array}$} & \multicolumn{2}{|c|}{$\begin{array}{l}\text { Collinearity } \\
\text { Statistics }\end{array}$} \\
\hline & & $\mathrm{B}$ & Std. Error & & Tolerance & VIF \\
\hline \multirow[t]{3}{*}{1} & (Constant) & 5.807 & 2.271 & & & \\
\hline & finger print & .191 & .180 & .182 & .589 & 1.699 \\
\hline & $\begin{array}{l}\text { motivasi } \\
\text { kerja }\end{array}$ & .557 & .178 & .536 & .589 & 1.699 \\
\hline
\end{tabular}

Berdasarkan Tabel 1 rangkuman nilai Tolerance dan VIF menunjukkan bahwa nilai Tolerance kedua variabel lebih dari 0,10 yaitu 0,589 dan nilai VIF kedua variabel lebih kecil $10 \%$ yaitu 1,699\%, sehingga bisa diduga bahwa tidak ada masalah multikolinearitas antar variabel independen dalam model regresi.

2. Uji Heteroskedastisitas

Model regresi yang baik adalah yang homokedastis atau tidak terjadi heteroskedastisitas. Homokedastis terjadi apabila varians dari nilai residual satu pengamatan ke pengamatan yang lain konstan (sama). Untuk mengetahui apakah terjadi heteroskedastisitas antar nilai residual dari observasi dapat dilakukan dengan melihat grafik scatterplot, yaitu dengan melihat ada tidaknya pola tertentu pada grafik.Jika tidak ada pola yang jelas serta titik-titiknya menyebar di atas dan di bawah sumbu 0 (nol) pada sumbu Y maka tidak terjadi heteroskedastisitas pada suatu model regresi.Berdasarkan hasil perhitungan dengan SPSS untuk variabel kedisiplinan pegawai $(\mathrm{Y})$ adalah sebagai berikut:

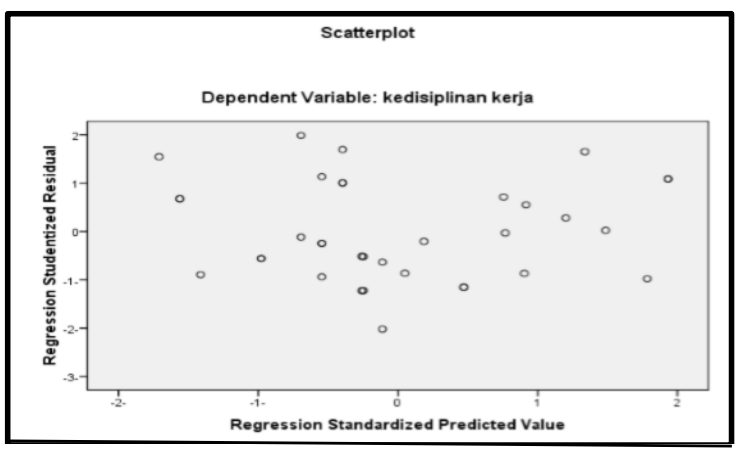

Gambar 1. Grafik scatterplot

Dari grafik scatterplot dapat diketahui bahwa titiktitik menyebar secara acak, tidak membentuk suatu pola tertentu yang jelas dan tersebar baik di atas maupun di bawah angka 0 (nol) pada sumbu $Y$. Sehingga dapat disimpulkan bahwa regresi yang dihasilkan tidak mengandung heteroskedastisitas.

3. Uji Normalitas

Uji normalitas digunakan untuk mengetahui apakah data yang disajikan untuk dianalisis lebih lanjut berdistribusi normal atau tidak. Untuk pengujian normalitas data, dalam penelitian ini hanya akan dideteksi melalui analisis grafik yang dihasilkan melalui perhitungan regresi dengan SPPS. Data yang normal ditandai dengan sebaran titik-titik data diseputar garis diagonal. Hasil pengujian normalitas data dapat dilihat sebagai berikut:

Normal P.P Plot of Regression Standardized Residual

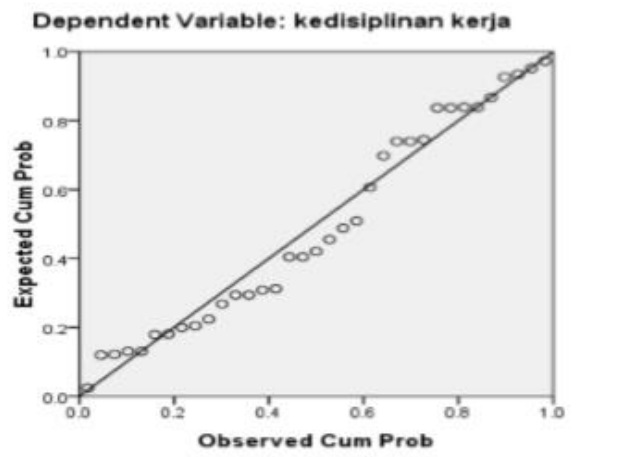

Gambar 2. Grafik scatterplotNormalitas

Begitu pula pada grafik normal P-P Plot residual penyebaran data terletak di sekitar garis diagonal dan mengikuti arah garis diagonal, sehingga bisa diartikan bahwa distribusi data kedisiplinan pegawai adalah normal, sehingga bisa dilakukan regresi dengan model linier berganda.

4. Uji Regresi Linear Berganda

Suatu model persamaan regresi linier berganda digunakan untuk menjelaskan hubungan antara satu variabel dependen dengan lebih dari satu variabel lain. Dalam penelitian ini model persamaan regresi linier ganda yang disusun untuk mengetahui pengaruh secara bersama-sama (serempak) antara variabel absensi sidik jari (finger print) (X1) dan motivasi kerja (X2) terhadap variabel kedisiplinan pegawai $(\mathrm{Y})$. Dalam regresi linier berganda, persamaan regresinya adalah $Y=\alpha+$ $\mathrm{b}_{1} \mathrm{X} 2+\mathrm{b}_{2} \mathrm{X} 2+\mathrm{e}$ yang digunakan untuk melakukan analisis secara simultan antara absensi sidik jari (finger print) (X1) dan motivasi kerja (X2) terhadap kedisiplinan pegawai $(\mathrm{Y})$. Dengan menggunakan bantuan alat olah statistik SPSS Windows versi 16.0 diperoleh hasil perhitungannya sebagai berikut:

Tabel 2.Uji Regresi Linear Berganda

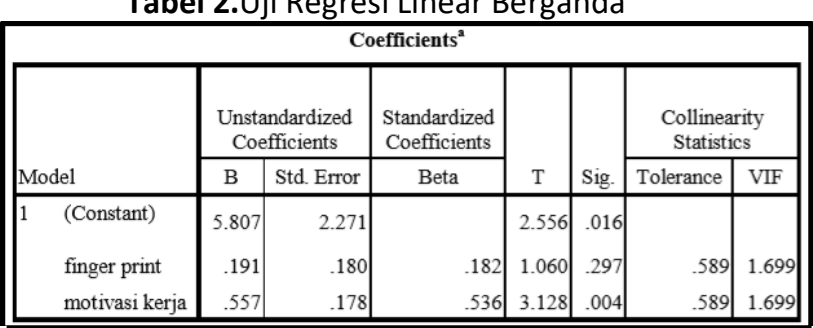


Berdasarkan hasil analisis regresi berganda pada Tabel 2 diperoleh koefisien untuk variabel bebas $\mathrm{X} 1=0,191, \mathrm{X} 2=0,557$ dan konstanta sebesar 5,807 sehingga model persamaan regresi yang diperoleh adalah:

$$
Y=5,807+0,191 \times 1+0,557 \times 2+e
$$

Dimana :

$\mathrm{Y}=$ Variabel dependen (kedisiplinan pegawai)

$\mathrm{X} 1=$ Variabel independen ( absensi sidik jari)

$\mathrm{X} 2=$ Variabel independen ( motivasi kerja)

$\mathrm{e}=$ Kesalahan pengganggu

a. Nilai konstan $(\mathrm{Y})$ sebesar 5,807 artinya jika variabel absensi sidik jari (X1) dan variabel motivasi kerja (X2) bernilai 0 (nol), maka variabel kedisiplinan pegawai $(\mathrm{Y})$ akan berada pada angka 5,807.

b. Koefisien regresi X1 (absensi sidik jari) dari perhitungan linier berganda didapat nilai coefficients $\left(b_{1}\right)=0,191$. Hal ini berarti jika absensi sidik jari (X1) dilaksanakan setiap hari secara disiplin maka volume kedisiplinan pegawai (Y) akan mengalami kenaikan sebesar 0,191\%. Dan karena koefiiennya bernilai positif maka terdapat hubungan yang positif antara absensi sidik jari dengan kedisiplinan pegawai.

c. Koefisien regresi X2 (motivasi kerja) dari perhitungan linier berganda didapat nilai coefficients $\left(b_{2}\right)=0,557$. Hal ini berarti jika pimpinan memberikan motivasi kerja (X2) lebih sering atau ada peningkatan $1 \%$ maka volume kedisiplinan pegawai (Y) akan mengalami kenaikan sebesar 0,557\%. Dan karena koefisiennya bernilai positif maka terdapat hubungan yang positif antara motivasi kerja dengan kedisiplinan pegawai.

\subsection{Pengujian Hipotesis}

Berikut ini adalah tahap-tahap yang dilakukan dalam pengujian hipotesis.

1. Uji Hipotesis secara Parsial (Uji T)

Untuk menguji pengaruh variabel independen terhadap variabel dependen secara parsial, digunakan uji Statistik T (uji T).Apabila nilai t hitung > nilai t tabel, maka $\mathrm{HO}$ ditolak dan $\mathrm{H} 1$ diterima, sebaliknya apabila nilai t hitung<nilai t tabel, maka $\mathrm{HO}$ diterima dan $\mathrm{H} 1$ ditolak. Hasil pengujian hipotesis secara parsial dapat dilihat pada berikut ini:

Tabel 3.Uji Parsial (Uji t)

\begin{tabular}{|c|c|c|c|c|c|c|}
\hline & & \multicolumn{5}{|c|}{ Uji Parsial (t) } \\
\hline & \multirow[b]{2}{*}{ Model } & \multicolumn{2}{|c|}{$\begin{array}{l}\text { Unstandardized } \\
\text { Coefficients }\end{array}$} & \multirow{2}{*}{$\begin{array}{c}\begin{array}{r}\text { Standardized } \\
\text { Coefficients }\end{array} \\
\text { Beta }\end{array}$} & \multirow[b]{2}{*}{ t } & \multirow[b]{2}{*}{ Sig. } \\
\hline & & B & Std. Error & & & \\
\hline \multirow[t]{3}{*}{1} & (Constant) & 5.807 & 2.271 & & 2.556 & .016 \\
\hline & finger print & .191 & .180 & .182 & 1.060 & .297 \\
\hline & motivasi kerja & .557 & .178 & .536 & 3.128 & .004 \\
\hline
\end{tabular}

Dari Tabel 3 dapat diketahui hasil dari variabel absensi sidik jari (finger print) (X1) menunjukkan t hitung 1,060 dengan nilai signifikan sebesar 0,297 atau di atas $5 \%(0,05)$. Artinya pengaruh variabel absensi sidik jari (finger print) terhadap kedisiplinan pegawai adalah tidak signifikan. Atau dengan kata lain $\mathrm{H} 1$ yang berbunyi "Ada pengaruh positif dan signifikan antara absensi sidik jari (finger print) terhadap pegawai" adalah ditolak.

Sedangkan hasil dari variabel motivasi kerja (X2) menunjukkan t hitung 3,128 dengan nilai signifikan sebesar 0,004 atau dibawah 5\% $(0,05)$. Artinya pengaruh variabel motivasi kerja terhadap kedisiplinan pegawai adalah signifikan. Atau dengan kata lain $\mathrm{H} 2$ yang berbunyi " Ada pengaruh positif dan signifikan antara motivasi kerja terhadap kedisiplinan pegawai" adalah tidak dapat ditolak.

\section{Uji Hipotesis secara Simultan (Uji f)}

Uji hipotesis secara serentak atau simultan (Uji F) antara variabel bebas absensi sidik jari (X1) dan motivasi kerja (X2) terhadap kedisiplinan pegawai (Y). Hasil analisis uji F dapat dilihat dalam berikut ini :

Tabel 4.Uji $\mathrm{f}$

\begin{tabular}{|c|c|c|c|c|c|c|}
\hline & \multicolumn{6}{|c|}{$\begin{array}{l}\text { Hasil Analisis Uji F (secara simultan) } \\
\text { ANOVA }^{\mathbf{b}}\end{array}$} \\
\hline \multicolumn{2}{|c|}{ Model } & $\begin{array}{l}\text { Sum of } \\
\text { Squares }\end{array}$ & $\mathrm{Df}$ & Mean Square & $F$ & Sig. \\
\hline \multirow[t]{3}{*}{1} & Regression & 56.140 & 2 & 28.070 & 12.879 & $.000^{2}$ \\
\hline & Residual & 69.746 & 32 & 2.180 & & \\
\hline & Total & 125.886 & 34 & & & \\
\hline
\end{tabular}

Uji simultan ditunjukkan dengan hasil perhitungan $\mathrm{F}$ test yang menunjukkan nilai 12,879 dengan tingkat probabilitas 0,000 yang dibawah alpha $5 \%(0,05)$. Hal ini berarti variabel independen antara variabel absensi sidik jari (finger print) (X1) dan motivasi kerja (X2) secara bersama-sama berpengaruh terhadap kedisiplinan pegawai (Y). Dengan demikian dapat disimpulkan bahwa $\mathrm{HO}$ yang menyatakan "Variabel absensi sidik jari (finger print) dan motivasi kerja tidak berpengaruh secara signifikan terhadap tingkat kedisiplinan pegawai" tidak sanggup diterima,yang berarti menerima Ha yang berbunyi "ada pengaruh positif dan sigifikan antara absensi sidik jari (finger print) dan motivasi kerja terhadap kedisiplinan pegawai".

\section{Koefisien Determinasi}

Analisis koefisien determinasi dilakukan untuk mengetahui seberapa besar nilai prosentase kontribusi variabel bebas terhadap variabel terikat. Dari hasil perhitungan melalui alat ukur statistik SPSS 16.0 for Windows didapatkan nilai koefisien determinasi sebagai berikut : 
Tabel 5.Koefisian Determinasi

\begin{tabular}{|l|c|r|r|r|r|}
\hline \multicolumn{1}{|c|}{} & & & & & \\
Model & $\mathrm{R}$ & $\mathrm{R}$ & Square & Adjusted & Std. Error of the \\
R Square & Estimate & $\begin{array}{c}\text { Durbin- } \\
\text { Watson }\end{array}$ \\
\hline 1 & $.668^{\mathrm{a}}$ & .446 & .411 & 1.47634 & 2.109 \\
\hline
\end{tabular}

Tabel 5 di atas menunjukkan bahwa 44,6\% variabel dependen (kedisiplinan pegawai) dapat dijelaskan oleh variabel independen (absensi sidik jari dan motivasi kerja), sedangkan sisanya $55,4 \%$ dipengaruhi oleh variabel lain yang tidak diteliti dalam penelitian ini. Hasil dari uji kofisien determinasi tersebut memberikan makna bahwa masih terdapat variabel independen lain yang mempengaruhi kedisiplinan pegawai.

\section{Kesimpulan}

Berdasarkan tujuan penelitian dari laporan ini, maka dapat disimpulkan bahwa:

1 Variabel penerapan absensi sidik jari (finger print $)(\mathrm{X} 1)$ tidak mempengaruhi terhadap kedisiplinan pegawai Dinas Pengendalian Penduduk Keluarga Berencana Pemberdayaan Perempuan dan Perlindungan Anak. Terlihat thitung $(1,060)<$ ttabel $(1,693)$, dengan tingkat signifikan 0,297 > 0,05 (5\%) yang berarti penerapan absensi sidik jari (finger print) tidak mempengaruhi kedisiplinan pegawai.

Variabel motivasi kerja (X2) mempunyai pengaruh yang signifikan terhadap kedisiplinan pegawai Dinas Pengendalian Penduduk Keluarga Berencana Pemberdayaan Perempuan dan Perlindungan Anak. Terlihat thitung $(3,128)>$ ttabel $(1,693)$, dengan tingkat signifikasi $0,004<0,05(5 \%)$ yang berarti motivasi kerja mempunyai pengaruh dalam kedisiplinan pegawai Dinas Pengendalian Penduduk Keluarga Berencana Pemberdayaan Perempuan dan Perlindungan Anak.

2. Variabel absensi sidik jari (finger print) (X1) dan motivasi kerja (X2) secara bersama-sama mempunyai pengaruh atau hubungan yang signifikan terhadap kedisiplinan pegawai Dinas Pengendalian Penduduk Keluarga Berencana Pemberdayaan Perempuan dan Perlindungan Anak. Terlihat dari nilai $R 2$ yaitu 0,446 yang berarti absensi sidik jari (finger print) (X1) dan motivasi kerja (X2) secara bersama-sama mempengaruhi kedisiplinan pegawai sebesar $44,6 \%$ sedangkan sisanya 55,4\% dipengaruhi oleh faktor lain.

\section{Daftar Pustaka}

[1] Andjarwati, T. Motivasi dari Sudut Pandang Teori Hirarki Kebutuhan Maslow, Teori Dua Faktor Herzberg, Teori X Y Mc Gregor, dan Teori Motivasi
Prestasi Mc Clelland. Jurnal IImu Ekonomi dan Manajemen Vol. 1 No. 1. 2015.

[2] Denziana, A. Indrayenti. dan Fatah, F. Corporate Financial Performance Effects Of Macro Economic Factors Againts Stock Return. Jurnal Akuntansi dan Keuangan Vol. 5 No. 2. 2014.

[3] Jusuf, H. Ariana, A. dan Winarsih. Pengembangan Aplikasi Sistem Absensi Dosen dengan Menggunakan Fingerprint (Sidik Jari Digital) di Universitas Nasional.Jurnal Rekayasa Teknologi Vol. 5 No. 1. 2013.

[4] Matondang. Validitas dan Rebialitas Suatu Instrumen Penelitian. Medan: Universitas

Negeri Medan. 2009

[5] Pradan, M dan Reventiary, A. Pengaruh Atribut Produk Terhadap Keputusan Pembelian Sepatu Merek Customade (Studi di Merek Dagang Customade Indonesia).Jurnal Manajemen Vol. 6 No. 1. 2016

[6] Priyo, R. Taher, A. dan Al Musadieq, M. Pengaruh Motivasi Kerja dan Disiplin Kerja Terhadap Kinerja Karyawan. Jurnal Administrasi Bisnis Vol. 11 No. 1. 2014

[7] Pujihastuti. Prinsip penulisan kuesioner penelitian. Jurnal Agribisnis dan Pengembangan : Wilayah Vol. 2 No. 1. 2010

[8] Saputra, T. Pengaruh Motivasi Kerja Terhadap Disiplin Kerja Pegawai pada Dinas Pemuda dan Olahraga Provinsi Riau. Universitas Lancang Kuning. 2015 